23 Rinaldi M, Perkins R, Glynn E, Montibeller T, Clenaghan M, Rutherford J. Individual placement and support: from research to practice. Adv Psychiatr Treat 2008; 14: 50-60.

24 Alverson H, Carpenter E, Drake RE. An ethnographic study of job seeking among people with severe mental illness. Psychiatr Rehabil J 2006; 30 : 15-22.

25 Schneider J, Slade J, Secker J, Rinaldi M, Boyce M, Johnson R, et al. SESAMI study of employment support for people with severe mental health problems: 12-month outcomes. Health Soc Care Community 2009; 17; 151-8.

26 Catty J, Lissouba P, White S, Becker T, Drake RE, Fioritti A, et al. Predictors of employment for people with severe mental illness: results of an international six-centre randomised controlled trial. Br J Psychiatry 2008; 192: 224-31.

27 Paulson RI, Post RL, Herinckx HA. Beyond components: using fidelity scales to measure and assure choice in program implementation and quality assurance. Community Ment Health J 2002; 38: 119-28.

28 Office of National Statistics. Annual Local Area Labour Force Survey. ONS, 2002.

29 Howard LM, de Salis I, Tomlin Z, Thornicroft G, Donovan J. Why is recruitment difficult? An investigation into recruitment difficulties during an RCT of supported employment for patients with severe mental illness. Contemp Clin Trials 2008; 30: 40-6.
30 Thornicroft G, Brohan E, Leese M, Sartorius N. Global pattern of experienced and anticipated discrimination against people with schizophrenia: a crosssectional survey. Lancet 2009; 373: 408-15.

31 Boardman J, Grove B, Perkins R, Shepherd G. Work and employment for people with psychiatric disabilities. Br J Psychiatry 2003; 182: 467-8.

32 Thornicroft G. Shunned: Discrimination against People with Mental Illness. Oxford University Press, 2006.

33 Bertram M, Howard L. Employment status and occupational care planning for people using mental health services. Psychiatr Bull 2006; 30: 48-51.

34 Rinaldi M, Hill R. Insufficient Concern: The Experiences, Attitudes and Perceptions of Disabled People and Employers towards Open Employment in one London Borough. Merton MIND, 2000.

35 Calsyn J, Allen G, Morse A, Smith R, Templehoff B. Can you trust self-report data provided by homeless mentally ill individuals? Evaluation Rev 1993; 17: 353-66.

36 Goldberg R, Seybolt C, Lehman A. Reliable self-report of health service use by individuals with serious mental illness. Psychiatr Serv 2002; 53: 879-81.

37 Liberman RP. Employment outcomes for SSA beneficiaries. Psychiatr Serv 2008; 59: 114-5.
Psychiatry in the movies

\section{Now this won't hurt a bit}

\section{Peter Byrne}

In the movies, general practitioners perform brain surgery as frequently as obstetricians call for towels and hot water. With the exceptions of intramuscular injections and mismanaged restraint, real-life psychiatric interventions are not physically painful, but cinema gave psychiatry a chamber of horrors beyond that of the dentist or surgeon.

Most early representations of sadistic psychiatrists were about emotional/psychological manipulation: by hypnosis (see the February 2009 issue, p. 116) or deception. Psychopathic psychiatrists inflict emotional wounds: A Fine Madness (1966), Bad Timing (1980) and Asylum (2005). The psychologist of Peeping Tom (1960), played in flashbacks by the film's director Michael Powell, deliberately manipulates his young son and creates a homicidal sadistic voyeur. Aligning psychiatry with state torture, Manchurian Candidate (1962) sees moral soldiers turned into cold killers to the apparent pleasure of their psychiatrist jailors, who boast 'not brainwashing, but dry-cleaning'. The brutal, aversive behavioural techniques of A Clockwork Orange (1971) attempt to condition a sadistic murderer against violence: self-referential scenes where Alex is forced to watch violent films in restraints with eyes forced open, evoke his earlier brutal behaviour. The Ludovico Technique is perfect for the quick-fix Home Office minster, but lacks understanding of morality or real choice. A remake would give Alex 'dangerous severe personality disorder' (DSPD). In The Jacket (2005), Dr Becker (Kris Kristofferson) uses drugs and brutal confinement in a coffin with sensory deprivation to punish his patientinmates.

In One Flew over the Cuckoo's Nest (1975), McMurphy (Jack Nicholson) receives two brutal procedures. First, unmodified electroconvulsive therapy (ECT) fails to control his mutinous behaviour: in this film, ECT is used to punish three patients in one sitting. Later McMurphy is lobotomised. Many who have seen the film recall this surgery as killing him, rather than his euthanasia leaving the impression of institutional murder.

The most harrowing scene of Regeneration (1997) is when electrode-happy Dr Yealland applies increasing voltage shocks to the vocal chords of an aphonic soldier. Our horror is amplified by electricity's dubious status as 'treatment'. Electricity always hurts as torture (Underground, 1995), punishment (Face/Off, 1997), or execution (Green Mile, 1999). It is a colourful means of dispatching villains: Goldfinger (1964) begins and ends with Bond's assassinations by electrocution. Drawing on discredited psychiatric claims of 'curing' homosexuality, the glamrock musician (Ewan McGregor) of Velvet Goldmine (1998) has received ECT as a child 'to knock the fairy out of him', such that he 'goes bonkers every time he hears an electric guitar'. The archetypal video nasty Child's Play (1988) murders its psychiatrist by applying continuous ECT to his brain, thereby frying it. The hunter has become the hunted. 